independent examiners on ESAOTE, MyLab60 using both grey scale and power Doppler technic. A semi-quantitative assessment of the peripheral joints was performed for detecting joint inflammation and determining the grade of synovial thickening and the degree of vascularization. Ultrasound features for active disease were correlated to the local expression of the studied miRNAs. SPSS was used for statistical analysis. Results: RA SF showed overexpression of miR-155 (in $79.17 \%, p=1.63 \times 10^{-4}$ ) and of miR-223 (in $79.17 \%, p=1.64 \times 10^{-3}$ ) when compared to HCs and both miRNAs could be used to differentiate RA patients from $\mathrm{HCs}\left(\mathrm{p}=8.0 \times 10^{-5}\right.$ and $p=2.8 \times 10^{-4}$, respectively). When we analyzed the correlation between the diagnosis, the expression of miRNAs and the changes on the musculoskeletal ultrasound examination we found a statistically significant correlation between the presence of synovitis and the degree of the power Doppler signal on MSUS and the local expression of miR-223 ( $p=6.19 \times 10^{-4}$ and $p=0.003$, respectively). SF levels of miR-223 correlated also with the degree of synovial hypertrophy on MSUS $(p=0.013)$. The results for miRNA-155 were not statistically significant. Conclusion: The correlation between the local expression of miR-223 and the ultrasound features of active joint inflammation shows that this miRNA might be a better candidate for local disease biomarker than miR-155. Further analysis with larger sets is needed to confirm if altered local miRNA expression could be used in the clinical practice as biomarker for disease activity especially in cases with subclinical synovitis. REFERENCES:

[1] Filková M, Aradi B, Šenolt L, et al. Association of circulating miR-223 and miR-16 with disease activity in patients with early rheumatoid arthritis. ARD, 2014; 73: 1898-1904

[2]Kriegsmann, M., Randau, T.M., Gravius, S. et al. Expression of miR-146a, miR-155, and miR-223 in formalin-fixed paraffin-embedded synovial tissues of patients with rheumatoid arthritis and osteoarthritis. Virchows Arch, 2016; 469, 93-100.

Acknowledgements: The study was supported by Grant 14-D/2012 and Grant 60/2013 funded by Medical University-Sofia.

Disclosure of Interests: Russka Shumnalieva: None declared, Darina Kachakova: None declared, Radka Kaneva: None declared, Zlatimir Kolarov Speakers bureau: Amgen, Pfizer, Novartis, Abbvie, Roche, Astra-Zeneka, Simeon Monov Speakers bureau: Amgen, Pfizer, Novartis, Abbvie, Roche, Astra-Zeneka DOI: 10.1136/annrheumdis-2021-eular.3828

\section{POS0579 LOCAL ADAPTATION OF RECOMMENDATION-BASED MATERIALS FOR SHARED DECISION-MAKING AND MANAGEMENT OF COMORBIDITY IN RHEUMATOID ARTHRITIS}

J. M. Alvaro-Gracia ${ }^{1}$, C. Barbazan ${ }^{2}$, J. F. Garcia Llorente ${ }^{3}$, S. Muñoz-Fernández ${ }^{4}$, A. Gomez-Centeno ${ }^{5}$, A. Urruticoechea-Arana ${ }^{6}$, M. A. Caracuel-Ruiz ${ }^{7}$, E. Loza ${ }^{8}$, J. Calvo ${ }^{9}{ }^{1}$ University General Hospital Gregorio Marañón, Rheumatology, Madrid, Spain; ${ }^{2}$ Complexo Hospitalario Universitario de Vigo, Rheumatology, 'Vigo, Spain; ${ }^{3}$ Hospital de Galdakao Usansolo, Rheumatology, Bilbao, Spain; ${ }^{4}$ University Hospital 'Infanta Sofía', Rheumatology, Madrid, Spain; ${ }^{5}$ University Hospital 'Parc Tauli,' Rheumatology, Sabadell, Spain; ${ }^{6}$ Hospital 'Can Misses', Rheumatology, Ibiza, Spain; ${ }^{7}$ University Hospital 'Reina Sofía', Rheumatology, Cordoba, Spain; ${ }^{8}$ Instituto de Salud Musculoesquelética, Rheumatology, Madrid, Spain; ${ }^{9}$ University Hospital of Araba, Rheumatology, Vitoria-Gasteiz, Spain

Background: Evolving the management of rheumatoid arthritis (eRA) is a European-wide educational initiative aiming to support improved patient care through practical and educational tools addressing specific unmet needs. The aims of the eRA program were: (1) To identify priority unmet needs with the greatest impact on disease outcomes; (2) To develop practical, educational and guidance tools in line with EULAR recommendations to address identified unmet needs; and (3) To improve RA management and patient care.

Objectives: To describe the process by which local adaptations were made of materials derived from evidence-based recommendations in a training programme in rheumatoid arthritis (RA).

Methods: A multidisciplinary Steering Committee (17 members, 12 countries) identified unmet needs within the management of RA and prioritised those with the greatest impact on patient outcomes. Practical educational tools addressing priority needs were then developed for dissemination and implementation by the rheumatology community across Europe, including shared decision making practises and a checklist for managing comorbidity in RA, among others. These materials were evaluated in detailed and discussed in small regional groups by practicing rheumatologists. Voting, open discussions and recommendations were extracted from the meetings.

Results: Thirty-five Spanish rheumatologists from diverse geographic regions discussed a comorbidity checklist and a shared decision making tool. The results of the local meetings were synthesised as (1) a judicious commitment to check agreed comorbidities, and (2) a list of barriers and facilitators for the implementation of shared decision making at the local settings. With regards to ways to implement the agreed list and periodicity, two issues standed-out: (1) patient education and (2) the need of easy access to information and the use of local organisational systems in place. With respect to shared decision-making, issues raised included messages for self-awareness, challenges, and practical facilitators.

Conclusion: Discussion, adaptation, and planning are needed before implementing any evidence-based recommendation and materials if we want to achieve a successful implementation. Further studies should demonstrate whether this initiative was successful in achieving the goals of improved patient care. Our experience could be used as a guidance or example for implementation elsewhere.

Disclosure of Interests: None declared

DOI: 10.1136/annrheumdis-2021-eular.3922

\section{POS0580 COMORBIDITY BURDEN IS HIGH IN RHEUMATOID ARTHRITIS AND SPONDYLOARTHRITIS PATIENTS STARTING BIOLOGICS AND PREDICTS THE INCIDENCE OF SERIOUS ADVERSE EVENTS DURING THERAPY}

I. Flouri ${ }^{1}$, A. Repa ${ }^{2}$, N. Avgustidis ${ }^{2}$, N. Kougkas ${ }^{2}$, A. Eskitzis ${ }^{2}$, A. Molla Ismail Sali $^{2}$, S. Pitsigavdaki ${ }^{2}$, K. Pateromichelaki ${ }^{2}$, E. Kalogiannaki ${ }^{2}$, M. Terizaki ${ }^{2}$ G. Bertsias ${ }^{2}$, P. Sidiropoulos ${ }^{2} .{ }^{1}$ University Hospital of Heraklion, Crete, Rheumatology Department, Heraklion, Crete, Greece; ${ }^{2}$ University Hospital of Heraklion, Crete, Rheumatology Department, Heraklion, Crete, Greece

Background: There is limited information on the burden of comorbidities in patients with rheumatoid arthritis $(\mathrm{RA})$ and spondyloarthritis $(\mathrm{SpA})$ in real-world clinical practice and its impact on the incidence of serious adverse events (SAE) during biologic disease-modifying anti-rheumatic drug (bDMARD) therapy. Objectives: To evaluate the number of comorbidities in patients with RA and $S p A$ initiating a bDMARD in everyday clinical practice and to explore its association with the occurrence of a SAE during therapy.

Methods: Prospective study of all patients who start any bDMARD treatment in a tertiary centre University Hospital. All comorbidities and SAEs (AEs necessitating hospitalization or resulting in significant incapacity/death) are registered by treating physicians. Comorbidities' number was evaluated using two different indices: total comorbidities count (CC) and Rheumatic Disease Comorbidity Index (RDCl). Statistical analysis was performed using multinomial logistic and Cox regression models. Results: A total of 799 patients were analysed, of which 428 (54\%) had $\geq 3$ comorbidities (Table 1). Comorbidity burden was higher in RA, however in multivariable analyses, comorbidities were not significantly associated with diagnosis, but mainly with increasing patient age. Patients received 1701 bDMARD treatments. During a follow-up of 4019 patient-years, 198 patients (RA:134, SpA:64) had a total of 295 SAE (RA: 217, SpA:78). Each one additional comorbidity in CC index was resulting in $16 \%$ increased adjusted risk for the first SAE [HR $(95 \% \mathrm{Cl})=1.16(1.12-1.20), \mathrm{p}<0.001]$, and each additional comorbidity of the $\mathrm{RDCl}$ index was resulting in $28 \%$ increased risk [ $\mathrm{HR}(95 \% \mathrm{Cl})$ $=1.28(1.20-1.37), p<0.001]$. Other baseline independent predictors of the first SAE were greater age $[\mathrm{HR}=1.04, p<0.001]$ and use of corticosteroids [HR=1.42, $p=0.006]$.

Table 1. Biologic treatments and clinical characteristics at baseline

\begin{tabular}{|c|c|c|c|c|}
\hline \multirow[t]{2}{*}{ Patients, $\mathrm{N}$} & Total & RA & SpA & $\mathrm{p}$ \\
\hline & 799 & 501 & 298 & \\
\hline Females, N (\%) & $535(67)$ & $404(81)$ & $131(44)$ & $<0.001$ \\
\hline Age, median (IQR) ét & $55(45-65)$ & $60(51-68)$ & $46(36-54)$ & $<0.001$ \\
\hline Disease duration, median (IQR) ع́tๆ & $6.0(2.5-13)$ & $5.4(3-11)$ & $7.4(2.0-15)$ & $<0.001$ \\
\hline Comorbidities count, median (IQR) & $3(1-5)$ & $3(2-6)$ & $2(1-4)$ & $<0.001$ \\
\hline Patients with no comorbidities, $\mathrm{N}(\%)$ & $103(13)$ & $43(9)$ & $60(20)$ & $<0.001$ \\
\hline Patients with 1 comorbidity, $\mathrm{N}(\%)$ & $134(17)$ & $77(15)$ & $57(19)$ & 0.172 \\
\hline Patients with 2 comorbidities, $\mathrm{N}(\%)$ & $134(17)$ & $76(15)$ & $58(19,5)$ & 0.118 \\
\hline Patients with $\geq 3$ comorbidities, $\mathrm{N}(\%)$ & $428(54)$ & $305(61)$ & $123(41)$ & $<0.001$ \\
\hline RDCl, median (IQR) & $1(0-2)$ & $2(0-3)$ & $1(0-2)$ & $<0.001$ \\
\hline Patients with $\mathrm{RDCl}=0, \mathrm{~N}(\%)$ & $267(33)$ & $128(25.5)$ & $139(47)$ & $<0.001$ \\
\hline Patients with $\mathrm{RDCl}=1, \mathrm{~N}(\%)$ & $185(23)$ & $119(24)$ & $66(22)$ & 0.665 \\
\hline Patients with $\mathrm{RDCl}=2, \mathrm{~N}(\%)$ & $163(20)$ & $113(23)$ & $50(17)$ & 0.057 \\
\hline Patients with $\mathrm{RDCl} \geq 3, \mathrm{~N}(\%)$ & $184(23)$ & $141(28)$ & $43(14)$ & $<0.001$ \\
\hline Total bDMARDs initiated by patients, $\mathrm{N}$ & 1701 & 1098 & 603 & \\
\hline Co-administered methotrexate, $\mathrm{N}(\%)$ & $946(56)$ & $674(61)$ & $272(45)$ & $<0.001$ \\
\hline Co-administered corticosteroids, N (\%) & $493(29)$ & $397(36)$ & $96(16)$ & $<0.001$ \\
\hline DAS28, median (IQR) (in RA and perSpA) & $5.8(4.9-6.6)$ & $5.8(5.0-6.6)$ & $5.4(4.2-6.3)$ & $<0.001$ \\
\hline BASDAI, median (IQR) (in axSpA) & - & - & $5.6(4.5-7.0)$ & \\
\hline
\end{tabular}

Conclusion: Patients with RA and SpA initiating a bDMARD treatment in realworld clinical practice have a significant comorbidity burden which increases with age and is an independent predictor for an SAE during therapy.

Acknowledgements: This research is co-financed by Greece and the European Union (European Social Fund- ESF) through the Operational Programme "Human Resources Development, Education and Lifelong Learning" in the context of the project "Reinforcement of Postdoctoral Researchers - 2nd Cycle" (MIS5033021), implemented by the State Scholarships Foundation (IKY).

Disclosure of Interests: None declared

DOI: 10.1136/annrheumdis-2021-eular.3956 